Vol.16, No.60, July 2021, 606-625

\title{
IMPACT OF FLOODING ON AIRPORTS USING REMOTE SENSING AND GIS TECHNIQUES
}

\author{
Maii Ahmed Mohamed Ali, Essam Fawaz, Mostafa h. a. Mohamed \\ Faculty of Engineering, Al-Azhar University \\ Faculty of Engineering, Al-Azhar University \\ Higher Institute of Engineering, 15th OF MAY \\ *Corresponding Author E-mail:mam2200@hotmail.com
}

\begin{abstract}
Floods are considered one of the worst weather-related natural disasters. They are sudden and highly unexpected following brief period of heavy rain. Egypt is subjected to flash floods, their impact vast areas causing serious damages with thousands of human injuries, economic losses and heavy damage to man-made features. According to the importance and criticality of severe rains that may lead to floods that make us thinking about making flood management to avoid risks resulting from it. Flood management is an approach that is virtually unknown in Egypt and has not been widely discussed despite the growing problem of widespread flood damage in recent years. This study aims to evaluate the comprehensive of flash flooding occurrences, impacts, and possible mitigation on the Airports. In this study, Alexandria (Borg El-Arab district) was selected for flash flooding vulnerability assessment, because it is a coastal city and exposed to heavy rains for long periods causing floods, especially Borg ElArab international airport, it's about $49 \mathrm{~km}$ away from Alexandria city in the southwestern direction, and it is $14 \mathrm{~km}$ away from the new city of Borg El Arab in the eastern direction. It was established to relieve Alexandria International Airport, the area of the airport is about 43,669 square meters, the airport served about 189,064 passengers and this number is expected to rise especially after the opening of the new terminal, Runway and other buildings in the airport. Using digital elevation model (DEM) implemented into a Geographic Information System (GIS), the climate maps and metalogical data of this study can help initiating appropriate measures to mitigate the probable hazards in the area. During this research review the impact of floods, how they predict their occurrence to the Disaster Risk Reduction and avoid of danger impacts on vital areas in cities through surveying techniques. how to protect the assets and infrastructure of the airport by predicting the crisis appropriate to mitigate the probable hazards in the airport.
\end{abstract}

KEYWORDS: Geographic Information System, Surveying, DTM, flash floods, Remote sensing, Aviation. 

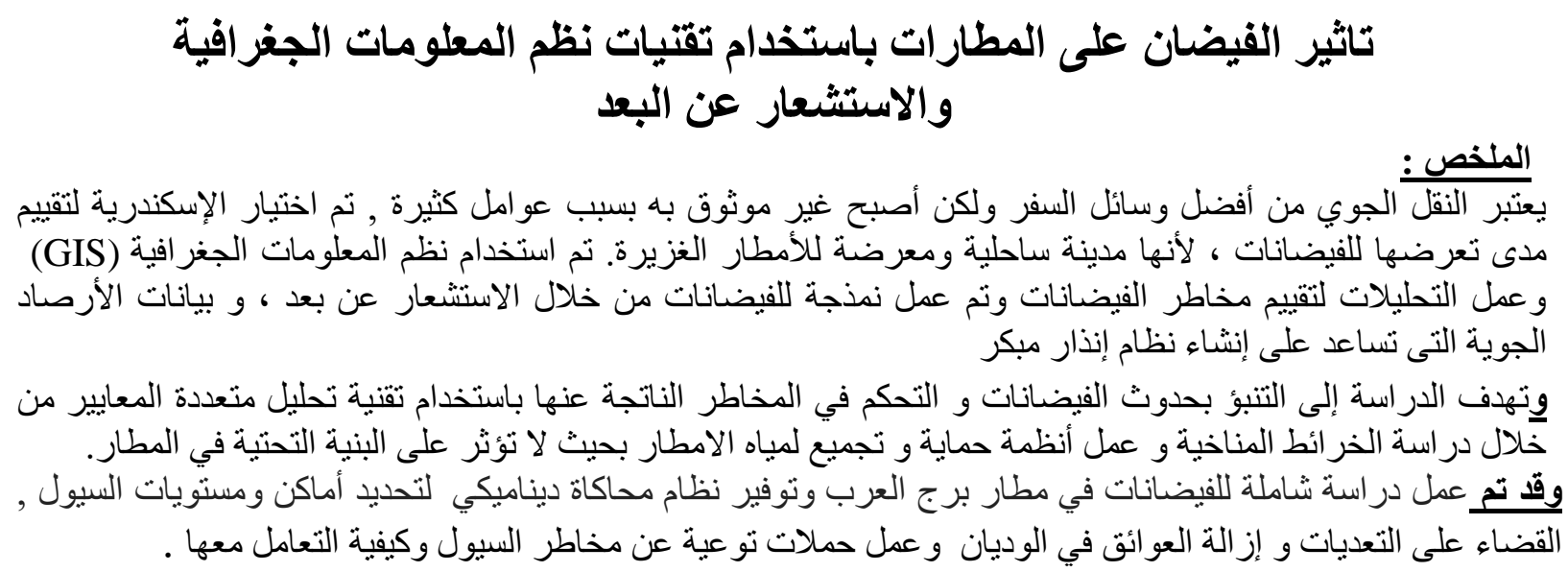

\section{1- INTRODUCTION}

According to the importance and criticality of severe rains that may lead to floods that make us thinking about making flood management to avoid risks resulting from it.

Flood management is an approach that is virtually unknown in Egypt and has not been widely discussed, despite the growing problem of widespread flood damage in recent years. [2]

Natural Crisis causes disturbances in the environment, such events are generally beyond the control of human beings Tornadoes, Earthquakes, Flood, Drought all result in natural disaster, Heavy and sustained rain over multiple days caused flooding and damage facilities and infrastructure as well as other resources.

Floods are caused by many factors: heavy precipitation, severe winds over water, unusual high tides, tsunamis, or failure of dams. [7]

Modelling flash floods is going to occur with the support of modern surveying techniques through remote sensing (analysis of satellite images), Geographic Information System (GIS) by determination of the ground elevation related to Mean Sea Level (MSL) to create digital elevation model (DEM).

Geographical Information System (GIS) is used to evaluate the linear, areal and relief characteristics of the qualitative and quantitative analysis for evaluation of flood hazard in the study area, its capable and comprehensive tools in flood crisis management issue more than before, climate maps and historical meteorological data will help us in finding ways to create Early Warning System (EWS) which help in Prediction of disasters and how to face it. [8] All of this will improve the process of harvesting rain water and find ways to reuse water in many different approaches to get the most benefits instead of wasting rain water.

After determining flood area in numerical map using search capability of geographic information system, finding information like access routes to damaged areas, health care stations, police, fire fighters, auxiliary forces, possible places for landing and takeoff airplane, some places for reserving flood and rescue devices, urban infrastructure like power plant, sewage system, communications, symmetry and the like and also risky material and places after flood crisis. [6]

Airports, by the very nature of their function, require a large area of very flat land to enable aircraft to take off and land safely. Historically, airports have been located in 'reclaimed' 607sea, since this is generally where the flattest land can be found.[9]

Rainfall has increased in the city of Alexandria, Borg El-Arab airport has been affected by some flood events, the terminal buildings have collapsed and some other constructions have exposed during this event. This research represents the anticipatory of flooding and protecting buildings structures and infrastructure in cities especially airports from flood risk danger, flash flood hazard phenomenon and runoff potentialities are the major task presents a new approach to modelling flash floods. 


\section{Airport's Impacts : reviews the impacts of airports and aviation}

Air transportation seems to be the best way of travels sometimes it became unsafely and unreliable due to the different factors including bad weather such as heavy rains, it may lead to aircraft accidents, delays, cancellations of flight and diversions of flights to other alternate aerodromes.

In the regions in which they are situated, and in some sectors of operation, such as tourism, airport infrastructure plays an important role. Owing to new consumer demands and new developments that have emerged in related markets, such as the air transport industry, their positions have changed in recent years.

The new positioning of airport infrastructures requires new strategies and a better management of resources and information, enabling the development of more innovative courses of action which are more appropriate to these new trends.[4]

The heavy rainfall across Egypt has caused floods, which affect Sharm El Sheikh airport was closed for several hours after rains destroyed parts of its ceiling, the city's main telephone communications center was severely damaged.[10]

The negative impacts of airports and aviation include noise, air pollution, climate change, positive impacts include direct and indirect jobs and social economic) benefits for people flying; these impacts can usually be separated into and likely closed down, impacts of airport building activities and related ventures.

Airport terminals and ground operations, flights, airport access (cars, buses, trains, parking facilities, etc. and associated projects, such as hotels and airports, related.[1]

A good flood forecasting system helps the concerned authorities in taking timely rescue and relief measures.

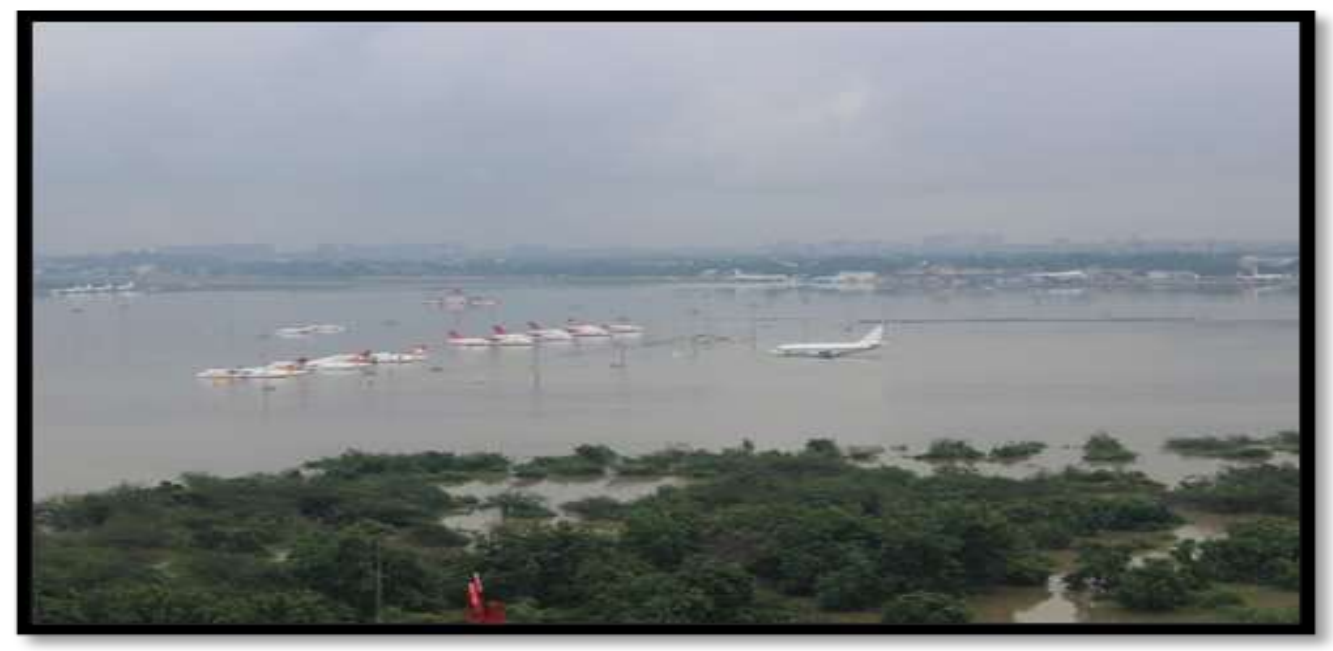

Fig. (1): Aerial view of submerged Chennai airport following floods

It is not only airport facilities that are at risk, but also access road networks, infrastructure networks and public transit systems that transport passengers and airport staff to and from the facilities. There are many forms of effects of flooding on the operation of an airport, the most evident of which is air traffic disruption. In terms of passenger and freight traffic.[7]

this in itself can cause significant economic losses. Even if a runway is clear of water, the movement of aircraft would also be inhibited by damage to airport facilities, such as landing lights, radar and navigation installations and communications networks. Flooding of airport terminals, emergency power plants and inter-terminal transport routes, evacuation of airports, flooding of access roads and transport networks encircling the airport would also affect operations. [8] 
Possible alternative to in flood-proofing. In combination with the construction of a dike and levee system, enhancing airport flood control could increase the ability of storm water systems for runways to be raised or partially elevated.

As part of the airport's resilience, more airport operators are recognizing the need to protect key facilities from the effects of flooding, constructing appropriate drainage systems not only for floodwater from runoff but also from overflow from nearby bodies of water.

Design adequate drainage systems not just for floodwater from rainfall but also from overflow from surrounding bodies of water, more airport operators are realizing the need to protect key infrastructure from the effects of flooding, as part of the airport's resilience. [7]

\section{2- Objective of study}

The aim of the research is to predict the occurrence of floods by studying the climate maps of site selection and taking the necessary precautions through early warning system (EWS) of disasters by using them in a proper way and to identify the places of water gatherings, catchment area so that they do not affect the infrastructure, vital installations at the airport and useful of this water in different ways.

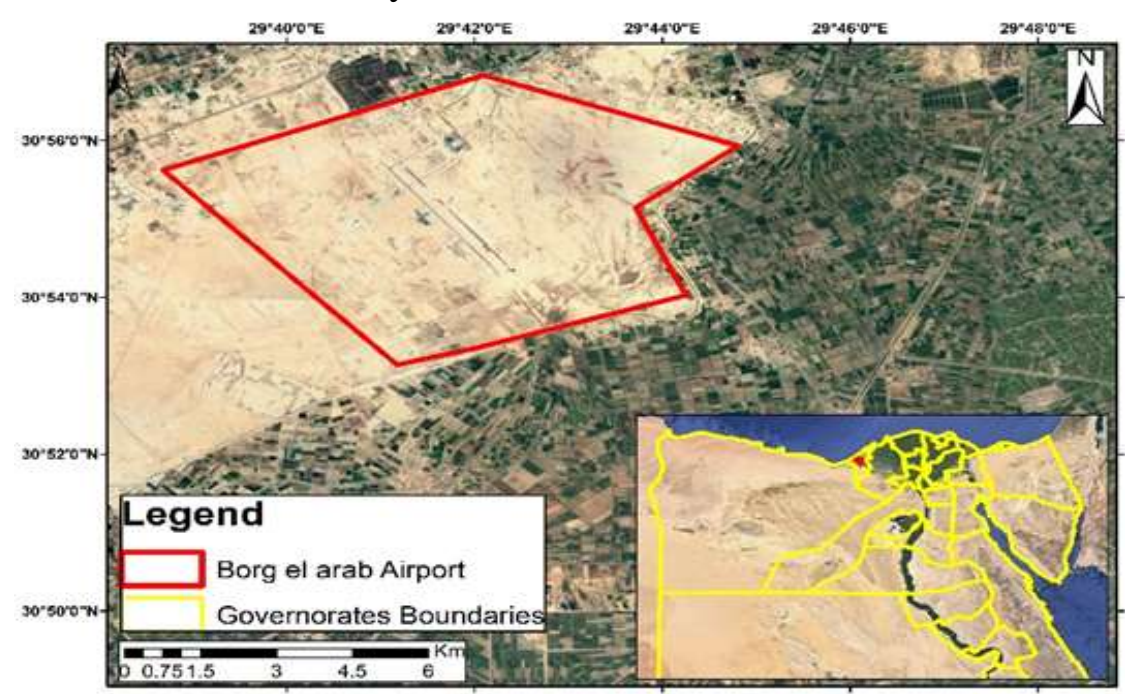

Fig. (2): Recent satellite image for Borg El-Arab Airport site location (Digital Globe 312020)

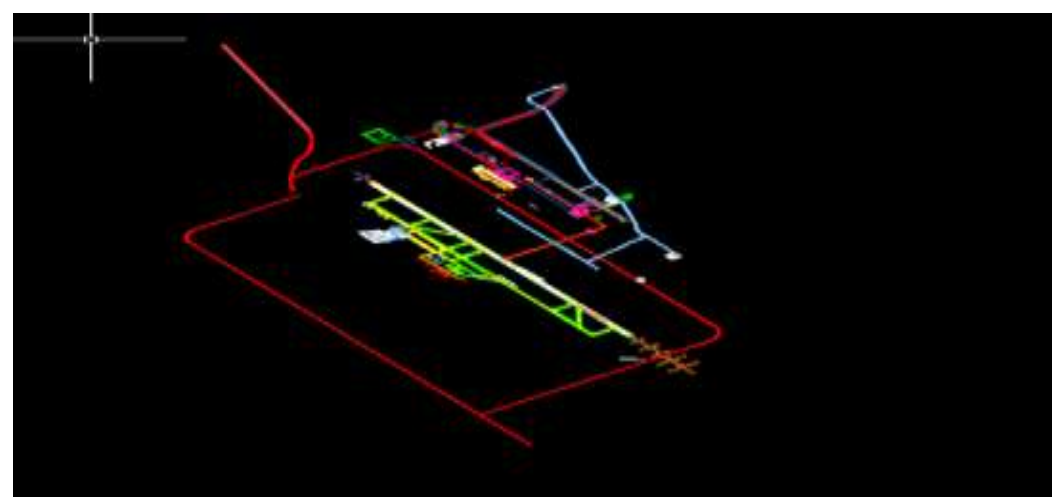

Fig. (3): Cad layout for Borg El-Arab Airport site location

Identify all features (building-navigation aids) related to the airport and Runways, evaluate how effective these rainfall thresholds are in predicting floods, enhance airport to anticipate and reduce impact of extreme weather events (now and in the future by foresight (hazard focused- temporal action. 
Make many alternatives to prevent crisis and save the work system sustainability reuse and recycling of water in agriculture and electricity generation, mitigation actions to prevent crisis during extreme weather incidences and adaptation actions to reduce the impacts of crisis knowledge exchange and capacity development on how to prepare for crisis, improved information and communication based on early warning and participatory flood resilience.

\subsection{General Description of the Study Area}

Borg El-Arab airport (Br) is located at the north of the Mediterranean Sea and $40 \mathrm{~km}$ southwest of Alexandria city. It

considers the third largest airport in Egypt with area of about $1246172 \mathrm{~m}^{2}$

Alexandria (Alex) is the second largest city of Egypt (surface area of 2,210 km2 with a $70 \mathrm{~km}$ coastline) and hosts $40 \%$ of the industry and the biggest port. The population of Alex is about 4.8 million and reaches 7 million in summer.

The Aerodrome have one Runway (RWY), named 14/32. Main specifications of each runway are summarized in Table 1.

Table 1: main specifications of Borg El-Arab airport runway [2]

\begin{tabular}{|c|c|c|c|c|c|}
\hline \multirow{4}{*}{$\begin{array}{l}\text { A defined } \\
\text { area on a }\end{array}$} & Runway & \multicolumn{3}{|c|}{ specifications } & \multirow{5}{*}{$\begin{array}{l}\text { rectangular } \\
\text { land } \\
\text { prepared }\end{array}$} \\
\hline & \multirow{4}{*}{$14 / 32$} & Type & \multirow{2}{*}{\multicolumn{2}{|c|}{$\begin{array}{l}\text { Existing RW } \mathrm{Y} \\
3400 \mathrm{~m} \times 45 \mathrm{~m}\end{array}$}} & \\
\hline & & Dimension & & & \\
\hline & & $\begin{array}{c}\text { Threshold } 14 \\
\text { coordinates }\end{array}$ & $30^{\circ} 55^{\prime} 44.78^{\prime \prime N}$ & $29^{\circ} 40^{\prime} 59.48^{\prime \prime} \mathrm{E}$ & \\
\hline aerodrome & & $\begin{array}{l}\text { Threshold } 32 \\
\text { coordinates }\end{array}$ & $30^{\circ} 54^{\prime} 16.77 " \mathrm{~N}$ & $29^{\circ} 42^{\prime} 16.79^{\prime \prime} \mathrm{E}$ & \\
\hline
\end{tabular}

and take- off of aircraft is runway, Runway determined by Threshold Coordinates, where the threshold coordinate is the geographic coordinates of the runway threshold at the center line and given for each instrument runway.

\section{3-Thematic Data}

The thematic data in airports such as runway, taxiways, aprons, movement area, maneuvering area, aircraft area service, buildings, utilities infrastructure, and public services places.

Surveying data can be obtained from the existing maps with scale map, (1:50000) surveying observations and measurements, aerial photographs, GPS observations, and other sources of surveying information.

Using new techniques are significant step forward and should be greatly recommended

Risk analysis techniques is a need in this study making a sustainable master plan for the airport is very important.

In the form of a risk, the outcome of the study identifies the strengths and weaknesses of the aerodrome and consists of a tool to help airport operators recognize where their efforts should be directed in order to improve their platform's resilience capability.

Today, in order to carry out the assessment, it is important to have a detailed knowledge of the climate forecast and all the necessary characteristics of airport components and overcome the crisis.[5]

\subsection{Observations and Measuring Survey Techniques}


The modern instruments in this field are:

\section{Total Station Instrument}

The total station, a combination of Electromagnetic Distance Measuring Instrument (EDM) and electronic theodolite, is an improvised variant of modern surveying methods. This combination makes it possible to determine the reflector co-ordinate by aligning the cross hair of the instrument with the reflector and calculating vertical and horizontal angles and slope distances at the same time. And in the instrument, a micro-processor takes care of recording, reading and the necessary computation, reading the data can be easily transferred to a computer, where it can be used for map generation, and the necessary computations.

Total Station in an airport is used to:

1. Determine coordinates.

2. Measure distances.

3. Take angular measurements.

4. Establish control surveys.

5. Perform contour and detail mapping.

6. Perform traverse stations.

7. Used in the purposes of construction engineer, design road construction, and levelling works.

8. used in compositing of profile levelling or L-section to determine the undulations of the ground surface.

9. Process the data.

\section{2- The Global Positioning System (GPS)}

The Global Positioning System (GPS) consists of a radio-navigation satellite constellation, a ground-based control segment that controls satellite operations and advanced receiver users that use satellite data to satisfy a broad range of positioning requirements.

The GPS in the airport is used to:

1. Measuring long distances with accuracy

2. Determining the coordinate on one global system with high accuracy

3. Establishing the fixed horizontal control points to be used in different surveying works

4. Establishing the triangulation networks of fixed horizontal control points

5. Planning works and setting out for the project

6. Performing contour and detail mapping

7. Creating traverse stations

8. Used in the purposes of construction engineer, design road construction, and levelling works

9. used in the compositing of profile levelling or L-section of the ground surface

\subsection{Sources of Data}

Surveying contributes to a large portion in collecting data from the field for GIS projects, the sources of surveying works are:

1- The existing maps

2- Global positioning system observations (GPS)

3- Satellite images

4- Other digital data, such as scanned maps and documents.

\subsubsection{GPS control points}

A marked point on the ground whose position is determined by triangulation.

The points have been observed by GPS instrument model 1230 GG for 2 hours where the point $93 \mathrm{BR}$ has been considered as a reference point, [3].

There are four triangle points surveyed in Borg Al-Arab airport, which are 93 BR, 94BR, 95BR, and 96BR, as shown in Figure (4). 
Every triangulation station has a description card as shown in Figure (5), [3].

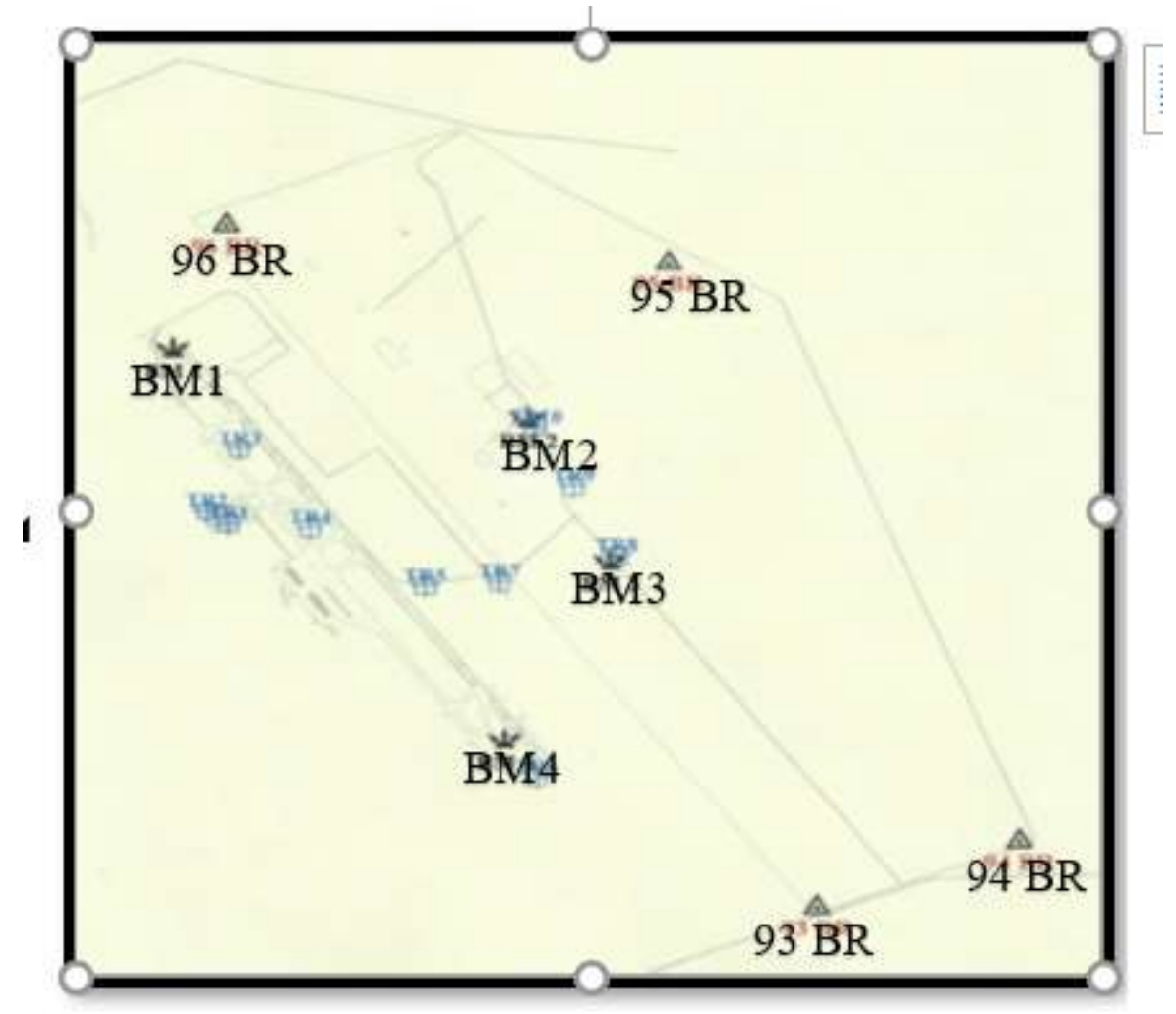

Fig. (4): Borg El-Arab Airport four GPS POINTS

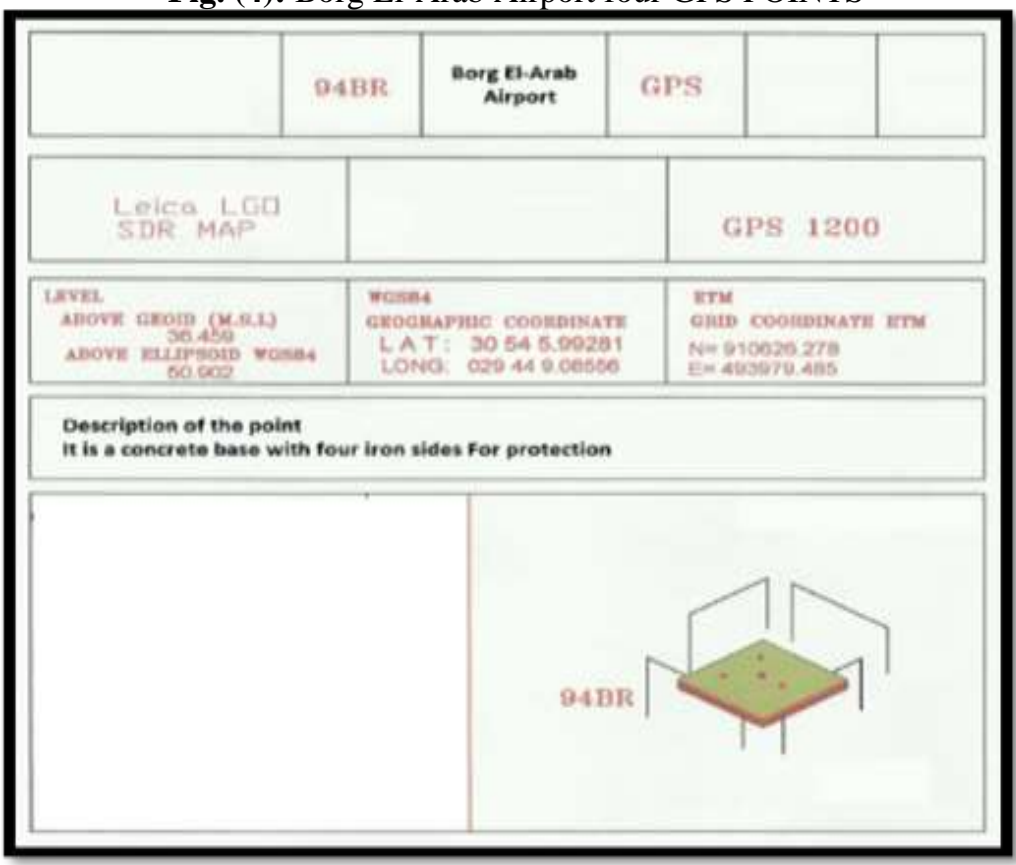

Fig. (5): Description card for GPS survey point 94BR.

(BR: Borg El-Arab)

\subsubsection{Bench Mark}

Surveyor's mark on a permanent object of predetermined position and elevation used as a reference point. There are 4 bench marks surveyed in Borg El-Arab Airport, which are BM1, 
BM2, BM3, and BM4, as shown in Figure (3). The reduced levels of the bench marks were determined using NA3003 level starting of the known bench marks and the levelling were checked and the closing error was within the limits $(10 \sqrt{\mathrm{K}})$, [8].

Every bench mark has a description card as shown in Figure (6), [9].

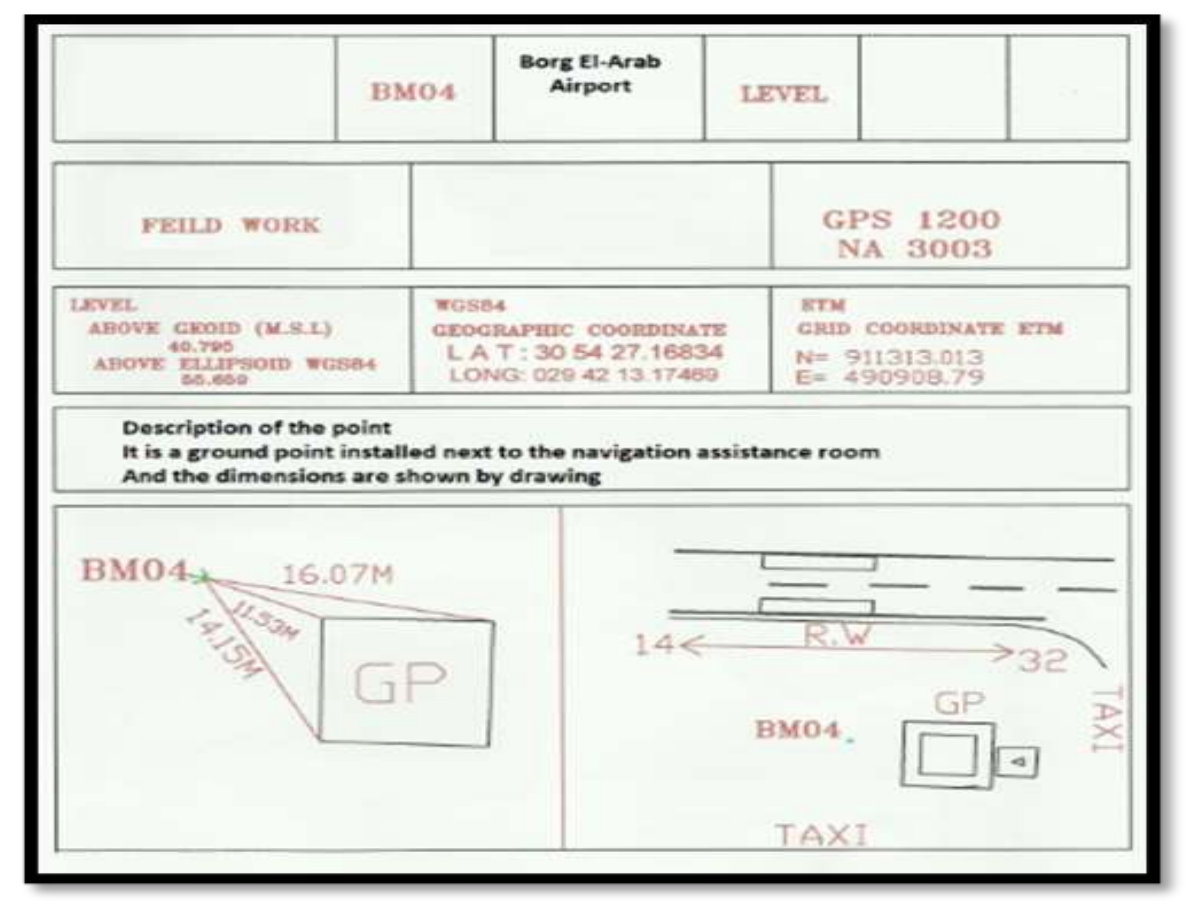

Fig. (6): Description card for Bench mark survey point BM04.

(BR: Borg El-Arab)

\subsection{Data collection and processing}

According to Field survey and recognize to the triangulation station which established in the airport, by making Surveying observation using GPS instruments model Leica 1200 for two hours considering point 94BR as reference, observe the point of first degree for 24 hours synchronous, after Survey all elevation points ( $\mathrm{z}$ value) then make data processing by using Leica Geo Office (LGO) software to obtain accurate coordinate its WGS84 reference system to produce DEM surface for the airport.

\subsection{Methodology}

- Data collection for airport (infrastructure- base map - digital elevation model- surveying data- satellite image)

- Historical data for meteorology (climate)

- Build a climate change scenario (temperatures - precipitations - Wind - sea level)

- Automatic detection of precipitation distribution forms the obtained data.

- Study the topography of studying area using remote sensing and GIS software.

- Study the characterization natural ground and classification to airport and its surrounding.

\subsection{Topography of the Airport}

\section{1- Determining Levels of Airport Area}

Inspecting of the 1500 ground levels at different locations, the highest ground level and the lowest ground level at Borg El-Arab airport area are: 
- The lowest ground level is $27.3 \mathrm{~m}$

- The highest ground level is $71 \mathrm{~m}$

\subsubsection{Topographic Map}

Topographic map covers airport area $15 \mathrm{~km}$ surrounding Borg El-Arab airport. Map scale is 1:50000. as shown in Figure (7).

Coordinate system: Universal Transverse Mercator

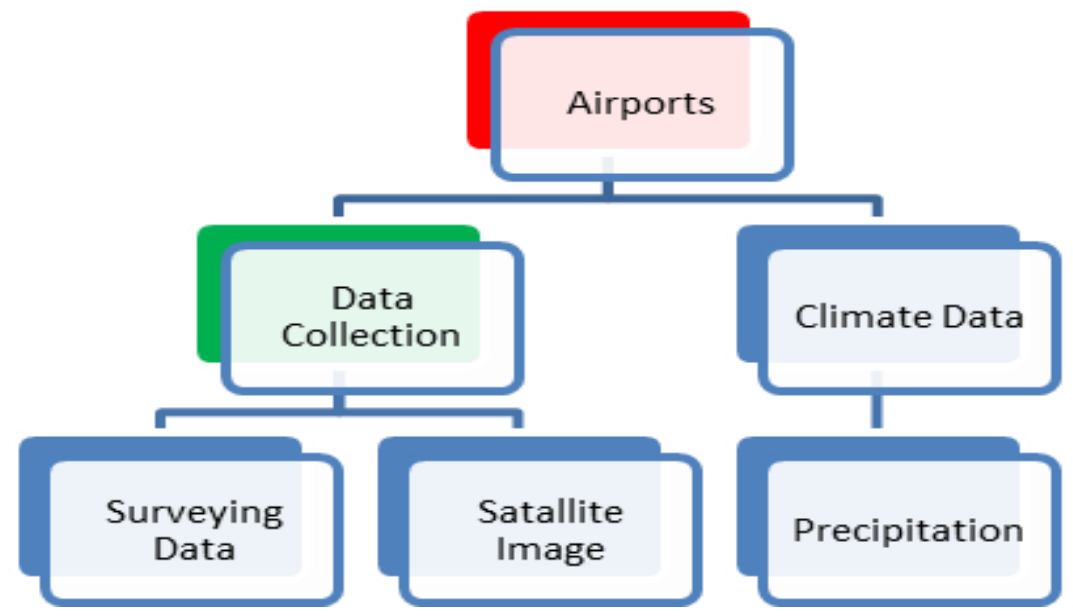

Source: The Egyptian General Authority of Survey

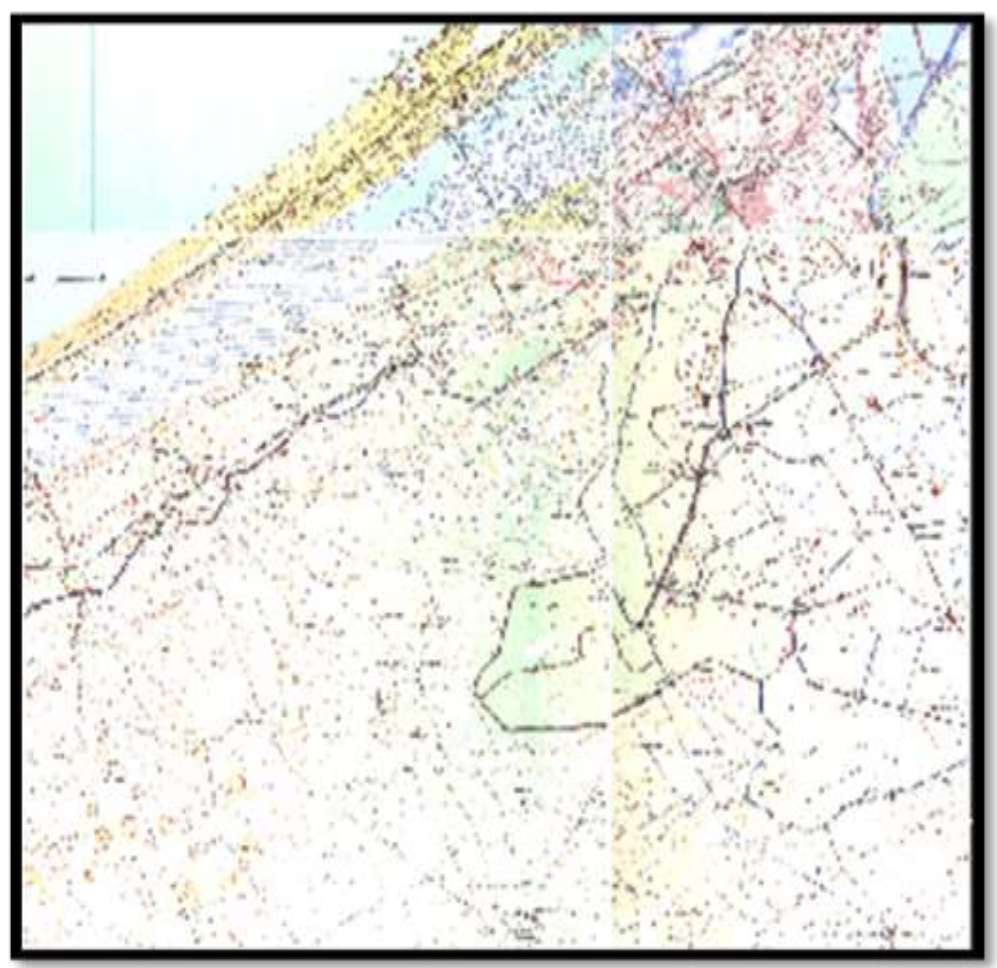

Fig. (7): Bog El-Arab topographic maps. Scale 1-50000

\subsubsection{Creation of Borg El-Arab DTM}


By using GIS Software 3D analyst tools (raster interpolation tool) which Interpolates a raster surface from points using an inverse distance weighted IDW technique with utilization the inspection points that have been mentioned before.

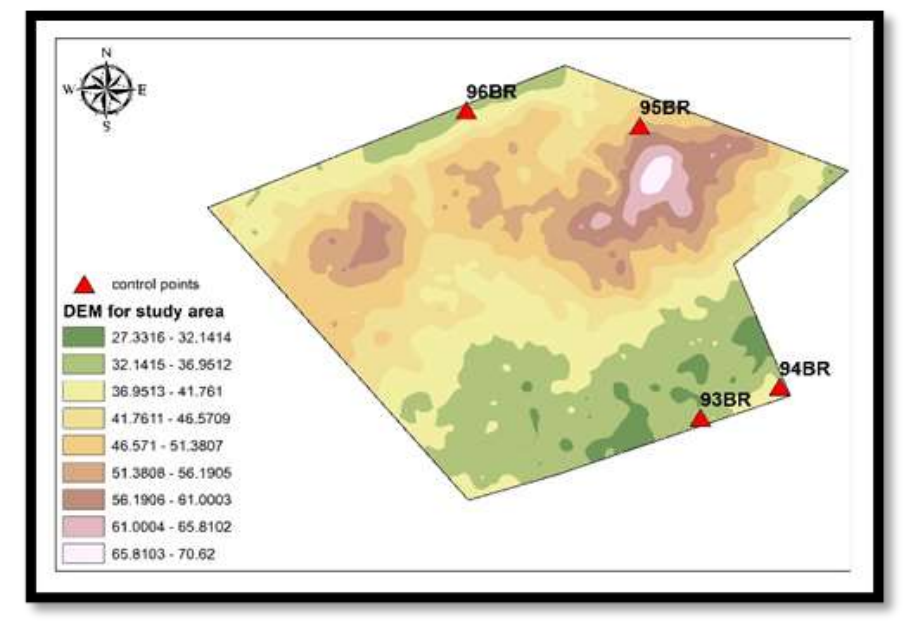

Fig (8): Create raster using elevation of points

Creating Borg El-Arab airport DTM in raster format using available data on points, lines and polygons, DTM is classified into multiple layers where each layer is characterized by different colors.

The tools for surface interpolation construct a continuous surface (or prediction) from sampled point values.

It is typically difficult or costly to visit any location in a study area to measure the height, concentration, or magnitude of a phenomenon. Instead at strategically scattered sampling locations, you can calculate the phenomenon, and expected values can be distributed to all other locations. Input points can be scattered or based on a sampling scheme either randomly or periodically.

Some measurements, such as height, concentration, or magnitude, represent the continuous surface representation of a raster dataset (for example, elevation, acidity, or noise level). (for example, elevation, acidity, or noise level). Surface interpolation methods, whether or not a measurement was taken at the location, allow predictions from sample measurements for all locations in an output raster dataset.

For each spot, there are a number of ways of deriving a prediction; each approach is referred to as a model. There are different assumptions made of the data for each model, and some models are more applicable to particular data, such as one model can better account for local variance than another. Using various equations, each model generates predictions.

In general, the techniques of interpolation are divided into deterministic and geostatistical approaches.

The deterministic interpolation methods assign values to locations based on the surrounding measured values and on specified mathematical formulas that determine the smoothness of the resulting surface.

The deterministic methods include IDW (inverse distance weighting), Natural Neighbor, Trend, and Spline.

The geostatistical methods are based on statistical models that include autocorrelation (the statistical relationship among the measured points). Because of this, geostatistical techniques not only have the capability of producing a prediction surface but also provide some measure of the certainty or accuracy of the predictions. 


\subsection{Create Contour Maps}

By using GIS Software 3D analyst tools (raster surface tool) which produce contour maps from elevation to create a line feature class of contours (isolines), as shown in figure (9).

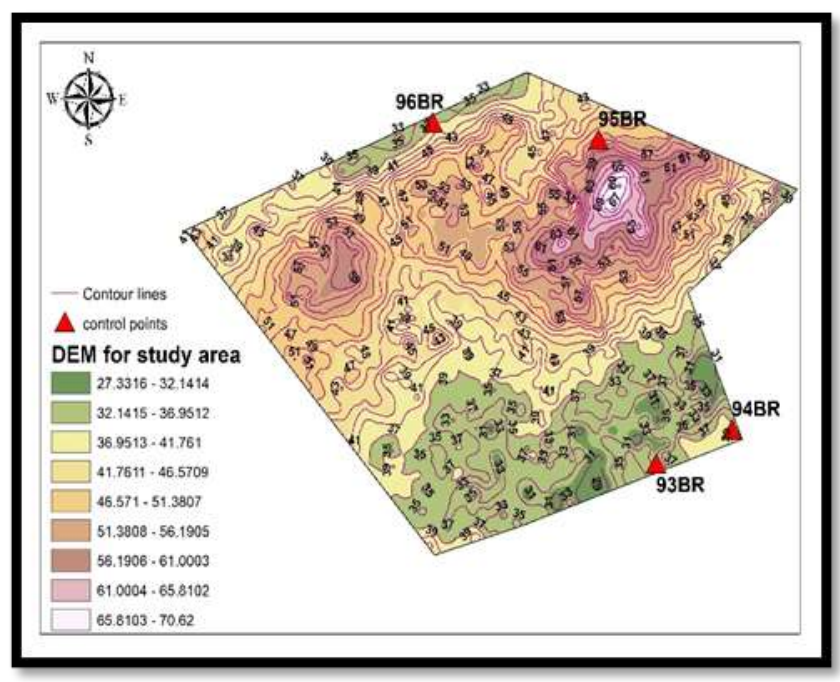

Fig (9): Contour map for airport area.

The previous figure illustrates that the north-eastern region of the airport represents the most dangerous rainwater collection area due to its rise and leads to a rapid rise of water towards vital areas Such as terminals, runways, apron and other constructions.

Due to the fact that the airport is located in a coastal city near by the sea which make it affected by the climate factors like rain according to its amounts and how intense also the wind according to its speed and direction.

By scanning maps or gathering aerial photographs and satellite images, Raster data is commonly obtained. Typically, scanned map datasets do not provide spatial reference information (either embedded in the file or as a separate file). The location information supplied with them is often insufficient with aerial photography and satellite imagery, and the data does not match properly with other data you have.

Therefore, you may need to align or geo reference them to a map coordinate system to use certain raster datasets in conjunction with your other spatial data. Using a map projection, a map coordinate system is defined (a method by which the curved surface of the earth is portrayed on a flat surface).

When you georeferenced your raster data, you define its position using map coordinates and assign the coordinate system of the data frame. Raster data georeferencing makes it possible to access, query, and analyze it with other geographic data. The Geo-referencing toolbar allows geo-referenced raster datasets, raster layers, image resources, and raster items to be used. The effect of using Techniques of Geographic Information System (GIS)

\section{Hydrologic analysis sample Applica Hydrologic analysis sample applications}

Methods for describing the physical components of a surface are given by the hydrologic modeling methods in the ArcGIS Spatial Analyst extension toolbox. The hydrological tools allow sinks to be defined, flow direction determined, flow accumulation measured, watersheds delineated, and stream networks established. applied GIS to model the rainfallrunoff process in Borg-al Arab airport.

The main objective of this study to located the critical points of basins water harvesting affecting vital features.

Geographic information systems use data From RS and other sources to build new georeferencing Databases in defined reference formats. 
Downloaded the dem of Borg-al Arab airport with buffering 10kg from downloading 30meter resolution elevation data from the Shuttle Radar Topography Mission (SRTM). [7]

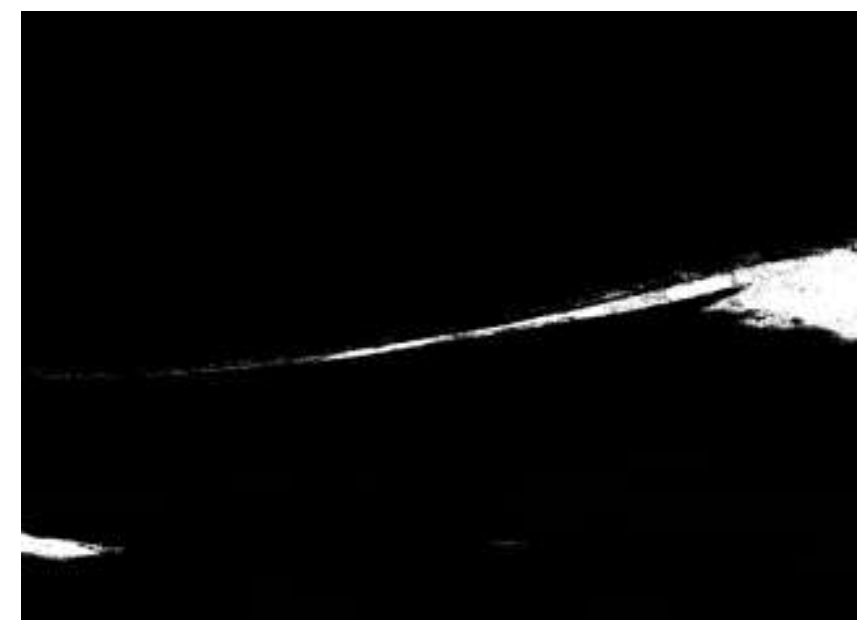

Fig (10): Dem surface of Borg-al Arab and its surrounding area

Fills sinks in a surface raster to remove small imperfections in the raster data.

\section{4- METHODE}

Processing and analysis of remote sensing and GIS data sets In the present study, all collected data were co-registered for unified projection (Datum; WGS 84, Universal Transverse, Spatial Analyst Tools (Hydrology Package) In the Arc Toolbox, stream network derived from elevation model can be automatically delineated using an elevation raster or digital elevation model (DEM) as input, The following graphics depict. The following graphics demonstrate the steps involved in estimating a network of watersheds and streams from a DEM. The flow direction and flow accumulation map of the next phase. Develops a flow path raster from each cell to its steepest downslope neighbor. Then a raster of the cumulative flow into each cell is formed. The DEM on which the hydrological research will be conducted. The direction in which water will flow out using the DEM as input to the Flow Direction function.

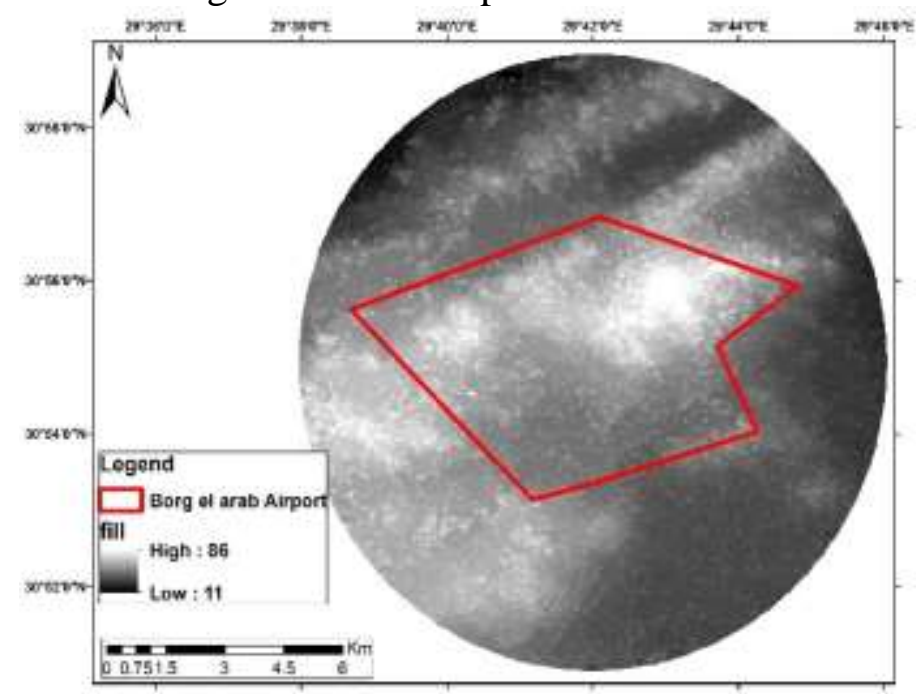

Fig (11): Using Fill tool on the Dem Surface

The next step flow direction and flow accumulation map. Creates a raster of flow direction from each cell to its steepest downslope neighbor. Then Creates a raster of accumulated flow into each cell. The DEM on which the hydrologic analysis will be performed.

Using the DEM as input to the Flow Direction tool, the direction in which water would flow out. 


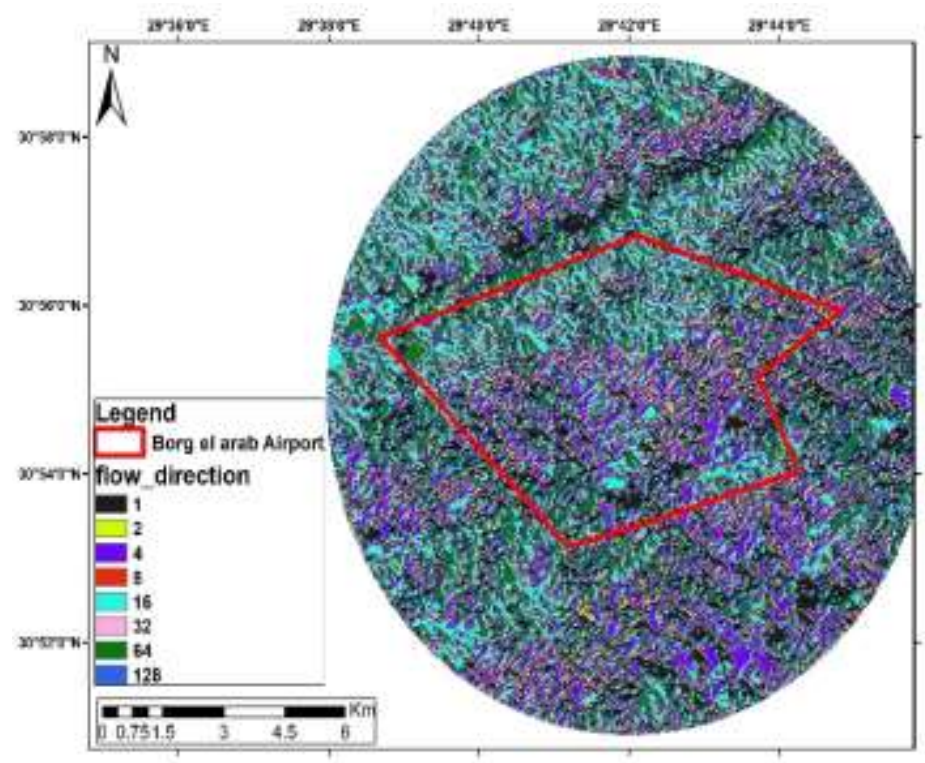

Fig (12): flow direction is determined

In the flow direction raster, the input raster that shows the direction of flow out of each cell.

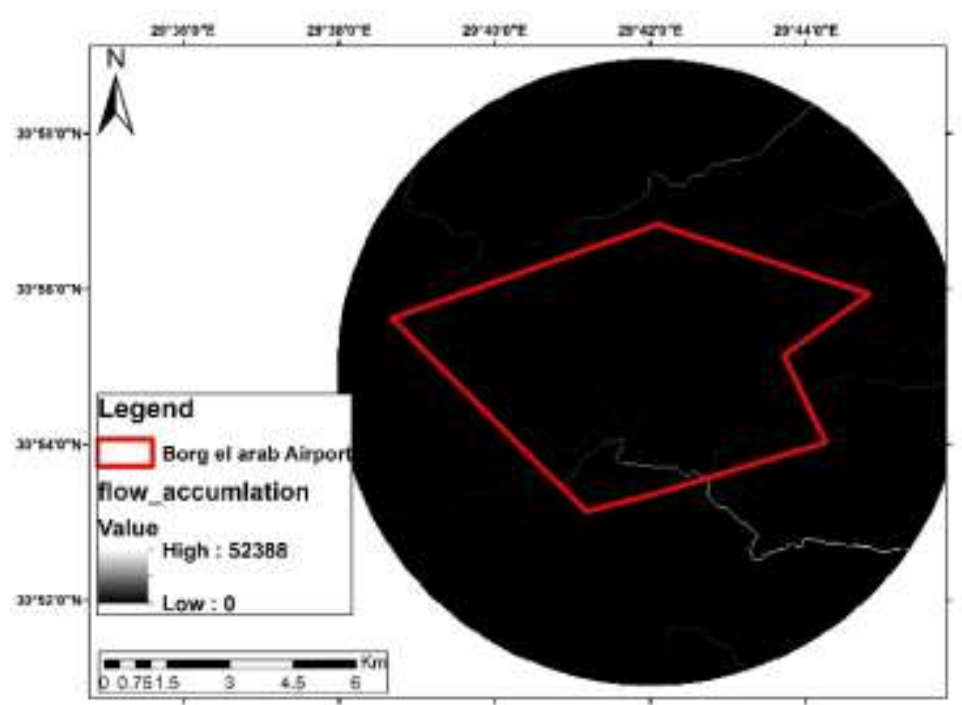

Fig (13): flow Accumulation output

The result of Flow Accumulation is a raster of accumulated flow to each cell, as determined by accumulating the weight for all cells that flow into each downslope cell.

After that take a step con from spatial analyst tool package conditional 


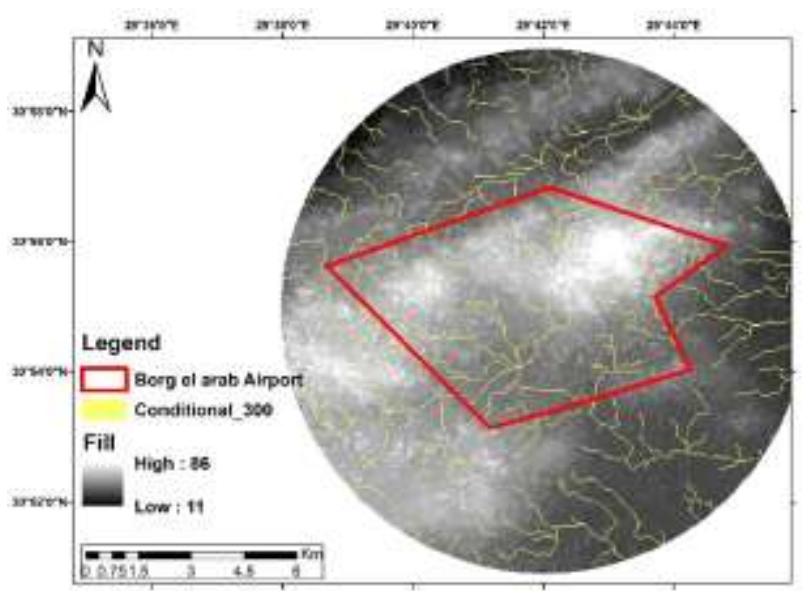

Fig (14): Performs a conditional if evaluation on each of the input cells of an input raster.

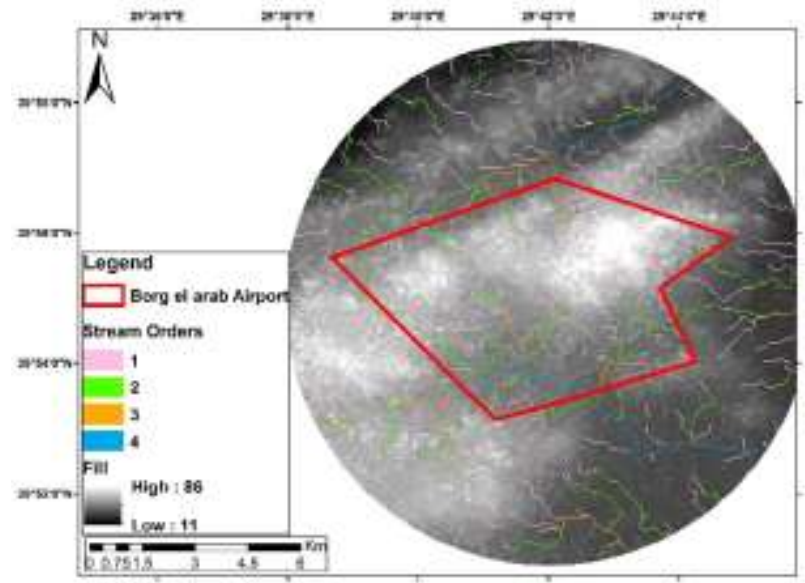

Fig (15): Output from Stream ordering

To represent the order of each of the segments in a network, apply the Stream Order Assigns a numeric order to segments of a raster representing branches of a linear network. The output of Stream Order will be of higher quality if the input stream raster and input flow direction raster are derived from the same surface. If the stream raster is derived from a rasterized streams dataset, the output may not be usable because, on a cell-by-cell basis, the direction will not correspond with the location of stream cells.

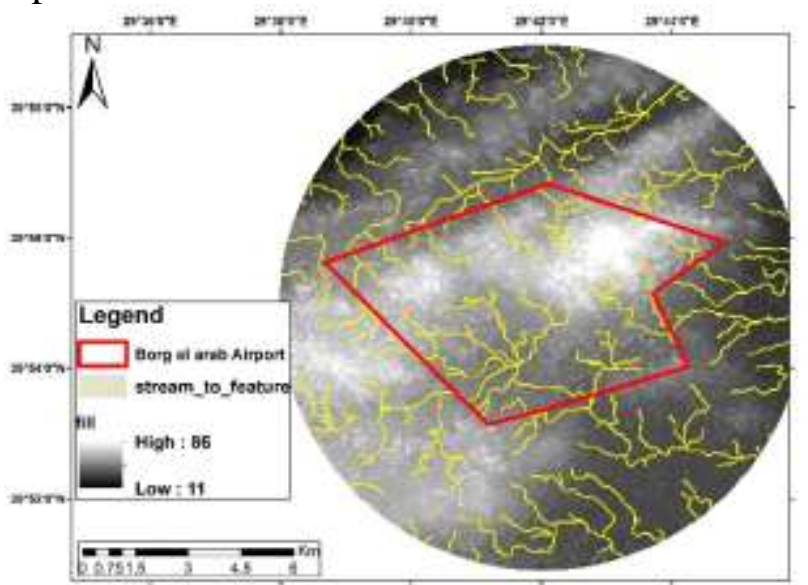

Fig (16): Output from Stream ordering 


\subsection{Stream to Feature}

Convert a raster describing a linear network to linear network characteristics. (vector) To build a raster stream network, the effects of the Flow Accumulation tool can be used by adding a threshold value to select cells with high accumulated flow. A linear stream network representing the input stream raster.

Raster-direction input flow. An input raster that indicates the flow direction of each cell. By using the Flow Direction tool, the flow direction raster can be generated.

\subsection{Stream order}

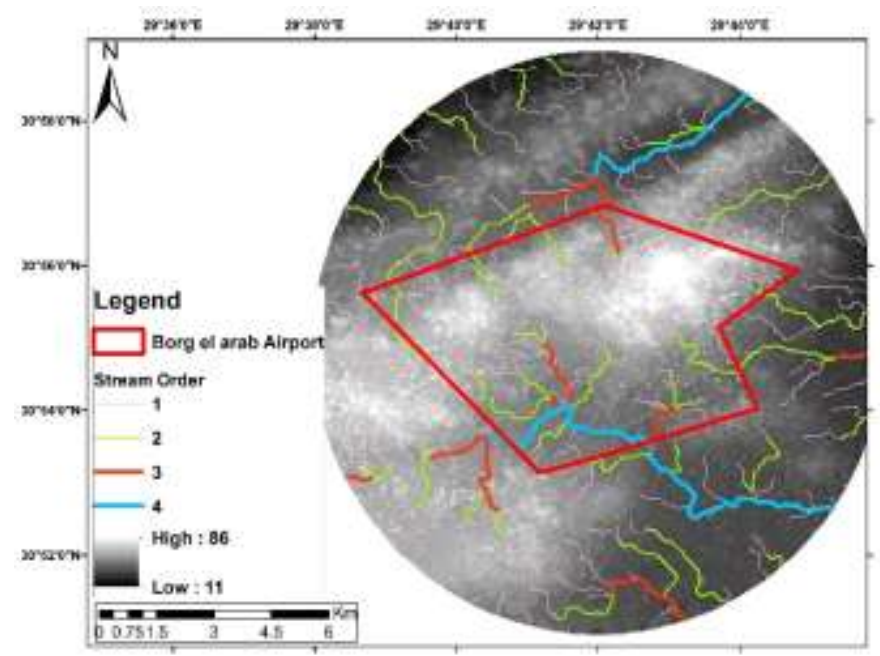

Fig (17): Output from Stream ordering

Assigns a numeric order to segments of a raster representing branches of a linear network.

When the input stream raster and input flow direction raster are extracted from the same surface, the output of Stream Order will be of higher quality. If a stream raster is extracted from a dataset of rasterized streams, the output might not be accessible because the path may not correlate with the position of the stream cells on a cell-by-cell basis.

\subsection{Basin}

Creates a raster delineating all drainage basins.

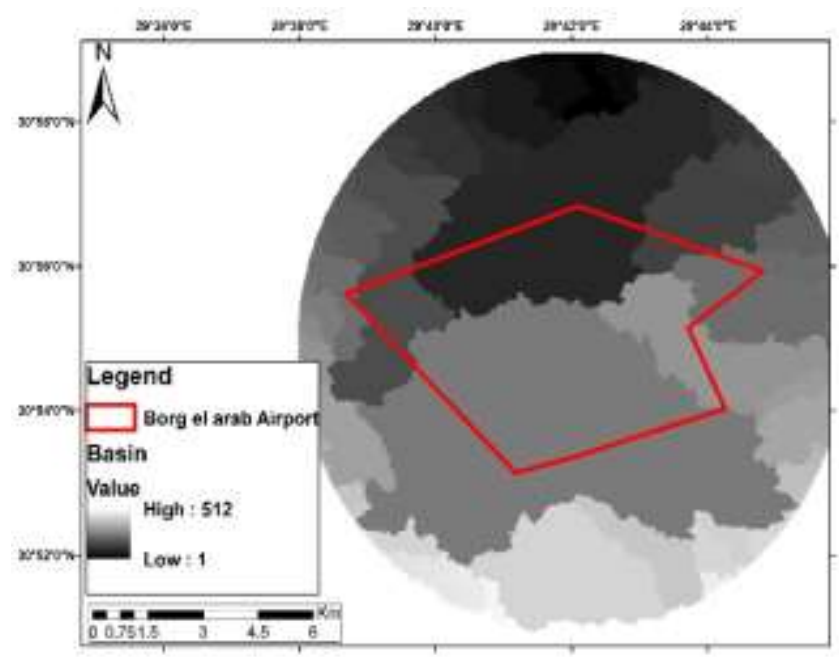

Fig (18): Output from Stream ordering

The drainage basins are delineated within the analysis window by identifying ridge lines between basins. The input flow direction raster is analyzed to find all sets of connected cells that belong to the same drainage basin. The drainage basins are created by locating the pour 
points at the edges of the analysis window (where water would pour out of the raster), as well as sinks, then identifying the contributing area above each pour point. This results in a raster of drainage basins.
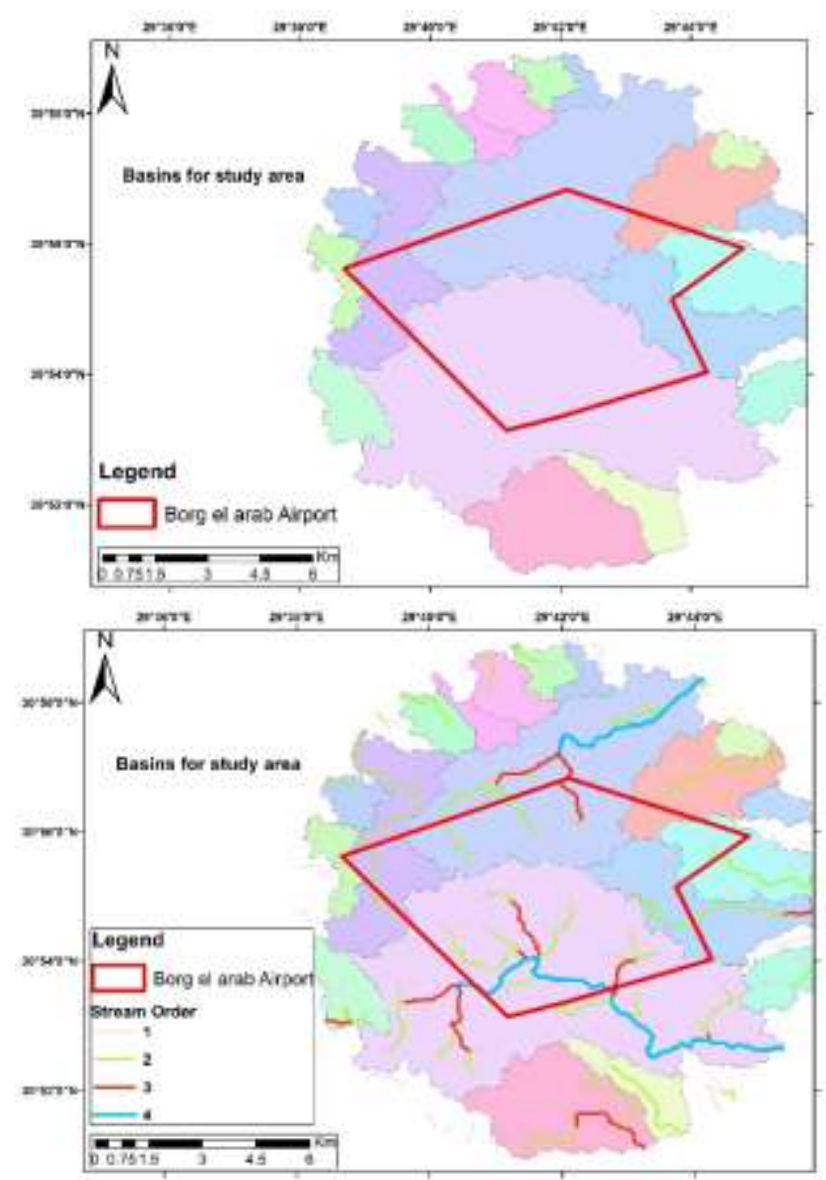

Fig (19): Basins for study area

The best results will be obtained from the hydrology package and determine the catchment area to collect and reuse water and take advantage of it. The degree of effect of runoff water was studied on the critical area at airport Such as runways, apron. Terminal, administration buildings, Power and fuel stations to protect them from any damage.

The flowchart represents circulation of hydrology package derived from the digital elevation model (DEM).

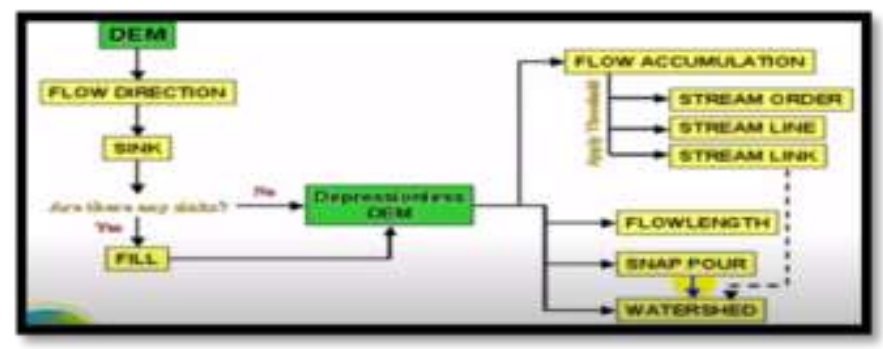

Fig (20): Flowchart represents circulation of hydrology package 


\subsection{Meteorological Data}

By previewing the study and its analysis this weather, factors and its impact throughout 18 years

Table 2: Observation of the half annual precipitation rate from 2000 to 2018

\begin{tabular}{|c|c|c|c|c|c|c|c|c|c|c|}
\hline LAT. & LONG. & 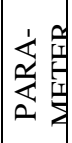 & 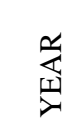 & 㤂 & $\frac{n}{\underline{T}}$ & $\stackrel{a}{\Sigma}$ & 包 & $\begin{array}{l}\text { z } \\
z\end{array}$ & $\begin{array}{l}\text { II } \\
\text { In }\end{array}$ & 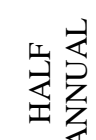 \\
\hline 30.92121 & 29.69151 & \multirow{19}{*}{ 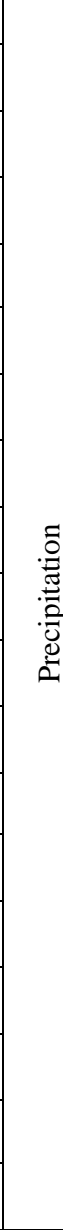 } & 2000 & 28.97 & 4.46 & 2.42 & 18.84 & 11.22 & 33 & 105.34 \\
\hline 30.92121 & 29.69151 & & 2001 & 18.88 & 7.05 & 3.59 & 8.41 & 4.5 & 20.38 & 64.58 \\
\hline 30.92121 & 29.69151 & & 2002 & 49.58 & 26.64 & 1.43 & 2.98 & 1.98 & 16.1 & 102.6 \\
\hline 30.92121 & 29.69151 & & 2003 & 6.34 & 16.57 & 14.86 & 0.17 & 6.6 & 20.08 & 65.01 \\
\hline 30.92121 & 29.69151 & & 2004 & 25.43 & 23.52 & 2.04 & 0 & 7.15 & 16.45 & 75.63 \\
\hline 30.92121 & 29.69151 & & 2005 & 13.46 & 5.68 & 5.7 & 1.38 & 6.05 & 16.23 & 52.12 \\
\hline 30.92121 & 29.69151 & & 2006 & 22.29 & 8.99 & 8.33 & 1.05 & 6.71 & 25.63 & 78.47 \\
\hline 30.92121 & 29.69151 & & 2007 & 9.02 & 16.15 & 4.21 & 0.84 & 4.58 & 21.56 & 65.71 \\
\hline 30.92121 & 29.69151 & & 2008 & 29.98 & 18.95 & 1.1 & 22.5 & 1.99 & 6.53 & 81.21 \\
\hline 30.92121 & 29.69151 & & 2009 & 1.76 & 23.54 & 3.15 & 6.01 & 5.63 & 4.52 & 45.44 \\
\hline 30.92121 & 29.69151 & & 2010 & 3.86 & 5.8 & 0.58 & 1.63 & 0.66 & 5.94 & 18.67 \\
\hline 30.92121 & 29.69151 & & 2011 & 13.5 & 8.16 & 3.91 & 0.61 & 39.62 & 5.74 & 83.52 \\
\hline 30.92121 & 29.69151 & & 2012 & 17.84 & 12.06 & 7.74 & 5.48 & 12.16 & 8.89 & 64.89 \\
\hline 30.92121 & 29.69151 & & 2013 & 28.02 & 2.57 & 0 & 0.01 & 2.92 & 21.04 & 60.34 \\
\hline 30.92121 & 29.69151 & & 2014 & 2.32 & 15.45 & 6.16 & 2.79 & 11.72 & 0.57 & 49.17 \\
\hline 30.92121 & 29.69151 & & 2015 & 15.17 & 20.22 & 8.32 & 9.59 & 32.19 & 31.37 & 156.66 \\
\hline 30.92121 & 29.69151 & & 2016 & 51.59 & 3.83 & 4.4 & 11.67 & 30.23 & 51.08 & 154.66 \\
\hline 30.92121 & 29.69151 & & 2017 & 5.68 & 12.94 & 0.33 & 21.1 & 20.86 & 8.7 & 192.83 \\
\hline 30.92121 & 29.69151 & & 2018 & 50.43 & 9.47 & 1.66 & 12.41 & 25.3 & 37.24 & 145.56 \\
\hline
\end{tabular}

Table 2 represent that the mean precipitation among the period from 2000 to 2018 was $84.26944 \mathrm{~mm} /$ year, the highest rate of precipitation happened in 2015 was $51.59 \mathrm{~mm}$ Caused damage in the infrastructure, disturbance of the airport and its impact on air navigation, the losses of airlines.[10] 


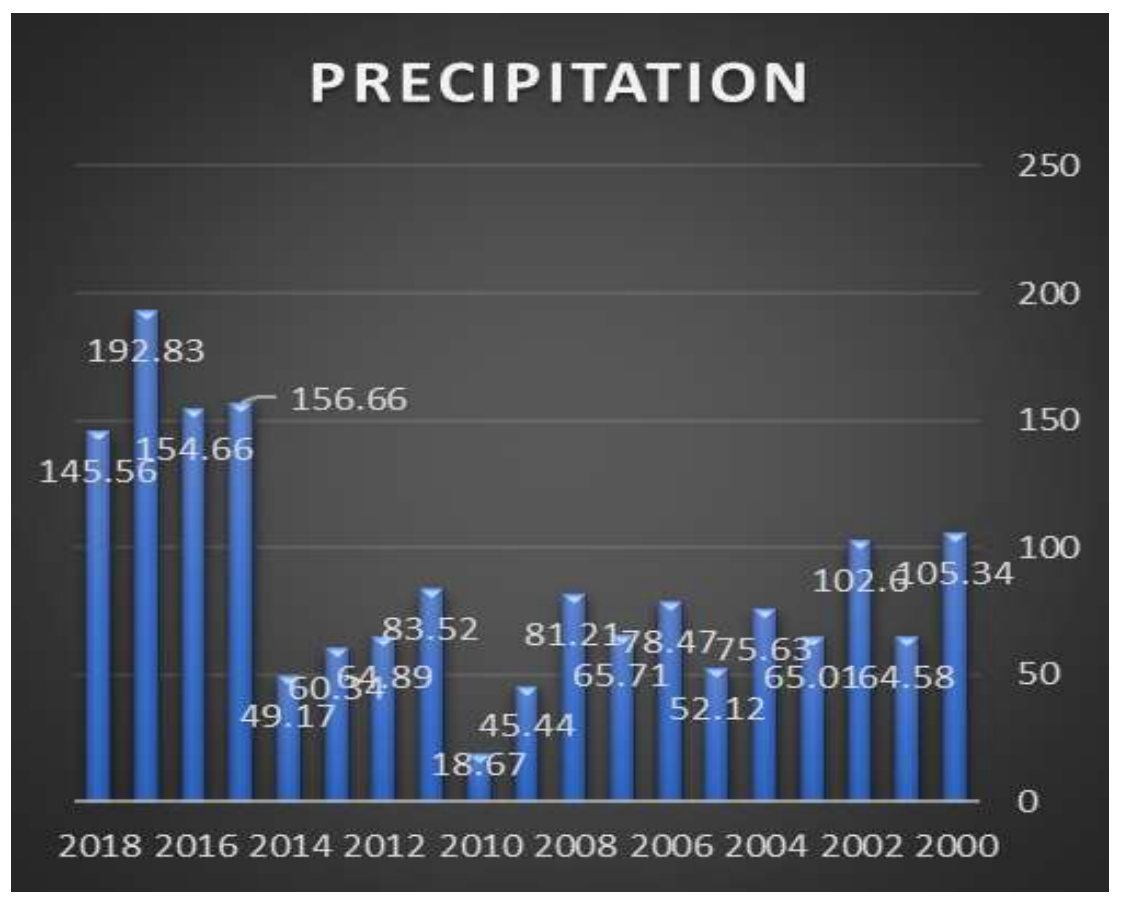

Fig (21): Bar Chart for Precipitation distribution according to years

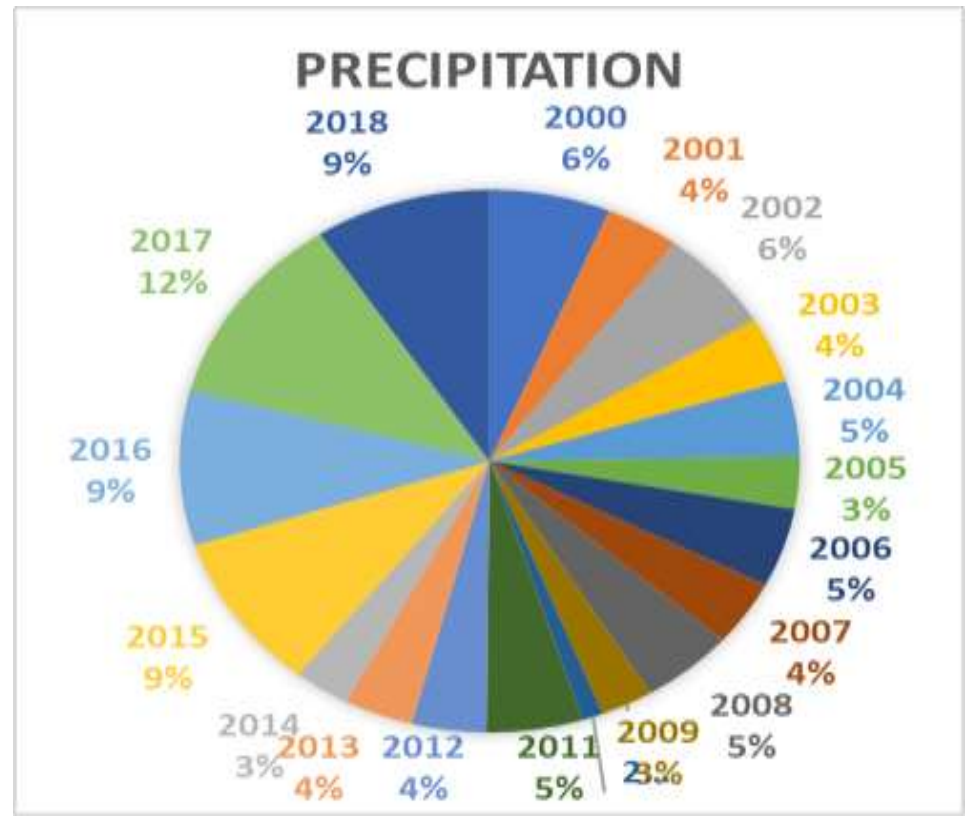

Fig (22): Pie Chart for Precipitation distribution according to years 


\section{5-Results}

flash flood depending on rain fall for long time with-out giving scale to the metrological parameters of the watersheds that cause flooding. The present study GIS and satellite metrological data were used for Borg al-Arab airport to estimate the flash flood. the probable flooded area related data base was constructed for the area of interest.

This paper presented how to control of flood events risk using multi criteria analysis technique.

After analyzing the results, it was found with the climatic changes that occur and the rainfall continuously for a long time, a flood occurs and affects the airport and vital constructions, and destruction occurs for them, so, must be taken in crisis management and take Benefits of climate forecasts.

1) protection tools such as retention dams (2) implementing commonly used structures

In order to minimize the impacts of flash flooding, store water behind these dams, and improve the usage of natural groundwater aquifers and take advantage of flood water for reuse, such as storage dams, cisterns, mitigation canals are strongly recommended.

\section{6-Conclusions and Recommendations}

GIS has become a useful tool for risk analysis. Maps allow decision makers to rapidly determine the possible impacts of natural hazards and further assist in launching effective impact mitigation initiatives.

Data helps planners and decision-makers during pre-disaster times to take correct and timely action.

Based on the study of drainage basins, GIS may classify areas impacted by flooding or predicted areas likely to be flooded. For flooding areas, maps of hazard assessment and vulnerability steps are simple to plan. In order to mitigate adverse flood impacts, precautionary steps may therefore be recommended in a timely manner.

Flash floods are a highly misunderstood hazard due to the infrequent nature of their occurrence and the lack of available data.

Nowadays, Flood mitigation is indispensable today. It complements other preventive methods, such as efficient urban development planning, by developing a computerized GIS database for flood-prone areas. To mitigate the damaging effects of these issues, comprehensive flood risk assessment location maps are needed. A Set of barriers (dams) at various location in the part of each basin may be built to avoid future flooding, the principal damaging effect due to the flash flood in Sharm el sheikh region is mainly caused by the transport of large boulder, the barriers will prevent the boulders from moving and store runoff. The early warning about the flooding has to be established to alarm people before the floods. Reporting occurs 3 days before climate change occurs from Egyptian Meteorological Authority The days they had to prepare for flooding: Sufficient period before the onset of winter (rainy season).

The coordination with other agencies in the department before, during and after the flooding: Coordination was carried out through the Governorate Operations and Crisis Management Room, where all parties involved in the crisis were coordinated (local units of the governorate - Water and Sanitation - Health - Catering - Airports)

Eliminate all encroachment on valleys and valleys that impede or change the direction of flood waters. Removing all obstacles in valleys or their estuaries, whether inside or in front of tourist villages. The construction of artificial lakes and dams to block flood water and benefit from it. Awareness campaigns on the dangers of floods and how to deal with them. There are competencies trained in crisis management and have accredited training courses, and also periodically specialists and citizens in the airports are trained in how to confront crises and disasters and conduct awareness-raising seminars in the airports, and through that they have the ability to confront crises, disasters and torrents in the airports 


\section{REFERENCES}

[1] Bowman, M., Debray, S. K., and Peterson, L. L. 1993. Reasoning about naming systems. ACM Trans. Program. Lang. Syst. 15, 5 (Nov. 1993), 795-825. DOI= http://doi.acm.org/10.1145/161468.16147.

[2] Brown, L. D., Hua, H., and Gao, C. 2003. A widget framework for augmented interaction in SCAPE. In Proceedings of the 16th Annual ACM Symposium on User Interface Software and Technology (Vancouver, Canada, November 02 - 05, 2003). UIST '03. ACM, New York, NY, 1-10. DOI= http://doi.acm.org/10.1145/964696.964697

[3] Ding, W. and Marchionini, G. 1997. A Study on Video Browsing Strategies. Technical Report. University of Maryland at College Park.

[4] Forman, G. 2003. An extensive empirical study of feature selection metrics for text classification. J. Mach. Learn. Res. 3 (Mar. 2003), 1289-1305.

[5] Fröhlich, B. and Plate, J. 2000. The cubic mouse: a new device for three-dimensional input. In Proceedings of the SIGCHI Conference on Human Factors in Computing Systems (The Hague, The Netherlands, April 01 - 06, 2000). CHI '00. ACM, New York, NY, 526-531. DOI= http://doi.acm.org/10.1145/332040.332491.

[6] Sannella, M. J. 1994. Constraint Satisfaction and Debugging for Interactive User Interfaces. Doctoral Thesis. UMI Order Number: UMI Order No. GAX95-09398., University of Washington.

[7] Spector, A. Z. 1989. Achieving application requirements. In Distributed Systems, S. Mullender, Ed. ACM Press Frontier Series. ACM, New York, NY, 19-33. DOI= http://doi.acm.org/10.1145/90417.90738.

[8] Tavel, P. 2007. Modeling and Simulation Design. AK Peters Ltd., Natick, MA.

[9] Yu, Y. T. and Lau, M. F. 2006. A comparison of MC/DC, MUMCUT and several other coverage criteria for logical decisions. J. Syst. Softw. 79, 5 (May. 2006), 577-590. DOI= http://dx.doi.org/10.1016/j.jss.2005.05.030.

\section{Web Sites References}

[10] www.aidforum.org/topics/water-sanitation/integrated-flood-management-ifm-a- newapproach-to-flood-management/

[11] http://floodlist.com/protection/flood-protection-options-airports

[12] https://www.meteoblue.com/en/weather/historyclimate/weatherarchive/31.276N32.243E5 Africa\%2FCairo?fcstlength $=1 \mathrm{y} \&$ year $=2019 \&$ month $=12$

[13] USGS, (Digital Globe 3\2020) (https://earthexplorer.usgs.gov 